and we hope to give a complete answer to this particular question in the near future.

The experiments described above were performed during the spring of the academic year 1934-35. We wish to thank Prof. The Svedberg and his associates for their interest and assistance with the work.

J. W. Williams.

Laboratory of Physical Chemistry, C. C. WATSON

\section{University, Upsala.*}

${ }^{1}$ Watson, Arrhenius and Williams, NATuRe, 137, 322 (1936).

* Present address: Department of Chemistry, University of Wis consin, Madison, Wisconsin, U.S.A.

\section{Some Infra-Red Bands in the $3 \mu$ Region}

IN view of recent communications ${ }^{1,2,3}$ on the infrared band arising from the $\mathrm{O}-\mathrm{H}$ vibration in certain compounds, it is of interest to direct attention to certain analytical data obtained by us with comparatively high dispersion in the region $3 \mu$, working with solutions about $0.1 \mathrm{~mol} / \mathrm{lit}$. in carbon tetrachloride.

In phenol, benzyl alcohol, diphenyl carbinol and triphenyl carbinol, we find that an intense $\mathrm{O}-\mathrm{H}$ band is obtained in each case, the wave-length being highest for phenol $(2 \cdot 770 \mu)$ and lowest for benzyl alcohol $(2 \cdot 764 \mu)$. The association band ${ }^{1}$ is found at 2.87-2.97 $\mu$, the wave-length increasing with the intensity of the band; its shape as shown in Fig. 1

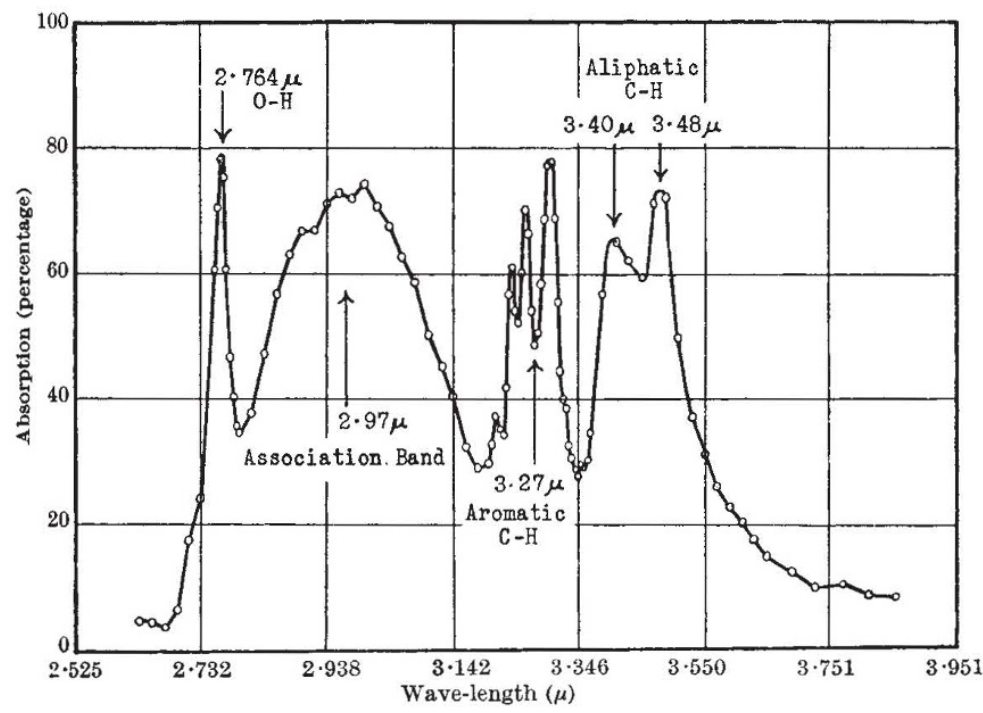

Fig. 1.

ABSORPTION OF A 1.3 MM. LAYER OF BENZYL ALCOHOL IN CARBON TETRACHLORIDE $(0 \cdot 169 \mathrm{MOL} / \mathrm{LTT}$. $)$ AT $18^{\circ} \mathrm{C}$.

for benzyl alcohol is similar to that for ethyl alcohol in carbon tetrachloride ${ }^{1}$. The intensity of the association band was about the same for phenol and benzyl alcohol, was less for diphenyl carbinol, and with triphenyl carbinol was visible as a small 'hump' on the general absorption at $2 \cdot 87 \mu$. These results suggest that the replacement of hydrogen by phenyl groups in benzyl alcohol suppresses intermolecular association.

Dilution was found to reduce the intensity of the association band in the case of phenol much more rapidly than the $\mathrm{O}-\mathrm{H}$ band (cf. Errera ${ }^{2}$ ). The former band dropped from 80 per cent absorption in 0.174 mol./lit. ( $\mathrm{O}-\mathrm{H}$ band 94 per cent) to $5 \frac{1}{2}$ per cent at $0.0145 \mathrm{~mol}$./lit. ( $\mathrm{O}-\mathrm{H}$ band 58 per cent). The triphenyl carbinol showed 12.5 per cent for the association band at $0.066 \mathrm{~mol}$./lit. as compared with 29 per cent for phenol at the same concentration.

Fig. 1 shows bands due to $\mathrm{OH}$ and association, the aromatic $\mathrm{C}-\mathrm{H}$ bands around $3 \cdot 27 \mu$ and the aliphatic $\mathrm{C}-\mathrm{H}$ bands at $3 \cdot 40$ and $3 \cdot 48 \mu$.

A full account of the bands of these and other organic compounds will be described elsewhere.

J. J. Fox.

A. E. Martin.

Government Laboratory, London. W.C.2.

Feb. 17.

1 Errera, J., and Mollet, P., Nature, 138, 882 (Nov. 21, 1936).

${ }^{2}$ Errera, J., Trans. Far. Soc., 33, 120 (1937).

${ }^{3}$ Buswell, A. M., Deitz, V., and Rodebush, W. H., J. Chem. Phys., 5, $84(1937)$.

\section{A Possible Acid-Dissociation of Metal-Ammonia Ions, and its Bearing on Certain Reactions}

RECENT observations ${ }^{1}$ on exchange reactions between heavy water and cobaltammines suggest a possible mechanism for certain reactions of the latter.

It would seem that the ammonia molecules in these complexes must, by co-ordination, have lost the ability to form ammonium ions, and therefore if we assume that the exchange reactions take place through the $\mathrm{D}+$ ion, we must con. clude that these co-ordinated ammonia groups can dissociate as acids :

$$
\begin{aligned}
& \left(\mathrm{Co} .6 \mathrm{NH}_{3}\right)^{3+} \rightleftarrows \\
& \quad\left({\left.\mathrm{Co} .5 \mathrm{NH}_{3} . \mathrm{NH}_{2}\right)^{2}+}_{+} \mathrm{H}+\right.
\end{aligned}
$$

This seems plausible, since the coordination of the analogous water molecule enables it, as is well known, to dissociate as an acid :

$$
\begin{gathered}
\left(\mathrm{Co} .5 \mathrm{NH}_{3} \cdot \mathrm{H}_{2} \mathrm{O}\right)^{3+} \rightleftarrows \\
\left(\mathrm{Co} .5 \mathrm{NH}_{3} \cdot \mathrm{OH}\right)^{2+}+\mathrm{H}^{+} ; \\
k=2 \times 10^{-6}
\end{gathered}
$$

The corresponding dissociation constant for the co-ordinated ammonia molecule would presumably be much smaller, but might still be appreciable.

On this basis it would be possible to account for the rapid replacement of acido-groups by hydroxyl ions :

$$
\begin{gathered}
\left(\mathrm{Co} .5 \mathrm{NH}_{3} . \mathrm{Br}\right)^{2+}+\mathrm{OH}-\overrightarrow{\mathrm{OH}}- \\
\left(\mathrm{Co} .5 \mathrm{NH}_{3} . \mathrm{OH}\right)^{2+}+\mathrm{Br}^{-}
\end{gathered}
$$

This reaction is unique, in that such replacements by other anions only take place much more slowly if at all. Alternatively, it may be regarded as catalysis by hydroxyl ion of an aquotization reaction,

$$
\left(\mathrm{Co} .5 \mathrm{NH}_{3} \cdot \mathrm{Br}\right)^{2+}+\mathrm{H}_{2} \mathrm{O} \rightarrow\left(\mathrm{Co} .5 \mathrm{NH}_{3} \cdot \mathrm{OH}_{2}\right)^{3+}+\mathrm{Br}-\text {, }
$$

followed by instantaneous establishment of the hydroxo-aquo equilibrium.

Now the kinetics of the aquotization of acido-aquo complexes have led to the conclusion ${ }^{4}$ that the hydroxo-acido ion undergoes this change much more rapidly than the aquo-acido ion with which it is in equilibrium, presumably in virtue of its smaller positive charge--a conclusion which harmonizes with 